\title{
16. Variable vs. Fixed Acoustics
}

Adjustable acoustics sounds like some sort of magical system which can provide ideal acoustical environment for a wide range of programs in a single hall.

Usually, such a system changes the reverberation time by adjusting the amount of acoustically absorptive material exposed to the space. This can take the form of absorptive curtains, banners, mats or baffles, and panels which alternately expose reflective or absorptive surfaces. In more extreme cases, there have been trials which change the effective acoustical room air volume by opening or closing reverberation chambers which in turn changes the reverberation characteristics of the space.

The adjustable acoustics systems are added as a selling point in halls which can then claim to be tunable for different programs from solo recital to chamber music to symphonic orchestral music. The systems are also intended to adapt to the difference between empty and occupied conditions, as moving from rehearsal to concert.

However, there are several problems with these "almighty" systems. First, who is responsible for making the decision to change the acoustics? While the principal conductor for a resident ensemble may have enough time and consistency in ensemble and program to play with the adjustable acoustics, touring orchestras will be at the mercy of even the most well-intentioned technical crew. I have heard of several examples where the crew changed the adjustable acoustics from the "rehearsal" to "concert" mode without informing the conductor. This completely defeated the point of rehearsals since the hall acoustics had changed entirely, akin to playing with a new orchestra.

Many acoustically excellent halls—such as Vienna Musikvereinssaal, Amsterdam Concertgebouw, Boston Symphony Hall, Berlin Philharmonie, Suntory Hall, and Walt Disney Concert Hall—do not have an adjustable acoustics system but accommodate many different concert types. Instead, the discussion should focus on programs such as pop and rock events, lectures, and musicals which require amplified sound systems. In these non-acoustic situations, absorbing materials like curtains, banner, or acoustical baffles would be indispensable. 